\title{
Rapid Deletion of Mossy Cells Does Not Result in a Hyperexcitable Dentate Gyrus: Implications for Epileptogenesis
}

\author{
Anna d. H. Ratzliff, Allyson L. Howard, Vijayalakshmi Santhakumar, Imola Osapay, and Ivan Soltesz \\ Department of Anatomy and Neurobiology, University of California, Irvine, California 92697
}

Loss of cells from the hilus of the dentate gyrus is a major histological hallmark of human temporal lobe epilepsy. Hilar mossy cells, in particular, are thought to show dramatic numerical reductions in pathological conditions, and one prominent theory of epileptogenesis is based on the assumption that mossy cell loss directly results in granule cell hyperexcitability. However, whether it is the disappearance of hilar mossy cells from the dentate gyrus circuitry after various insults or the subsequent synaptic-cellular alterations (e.g., reactive axonal sprouting) that lead to dentate hyperexcitability has not been rigorously tested, because of the lack of available techniques to rapidly remove specific classes of nonprincipal cells from neuronal networks.

We developed a fast, cell-specific ablation technique that allowed the targeted lesioning of either mossy cells or GABAergic interneurons in horizontal as well as axial (longitudinal) slices of the hippocampus. The results demonstrate that mossy cell deletion consistently decreased the excitability of granule cells to perforant path stimulation both within and outside of the lamella where the mossy cell ablation took place. In contrast, ablation of interneurons caused the expected increase in excitability, and control aspirations of the hilar neuropil or of interneurons in the presence of GABA receptor blockers caused no alteration in granule cell excitability.

These data do not support the hypothesis that loss of mossy cells from the dentate hilus after seizures or traumatic brain injury directly results in hyperexcitability.

Key words: epilepsy; mossy cell; hyperexcitability; hilar cell loss; dentate gyrus; dormant basket cell hypothesis

\section{Introduction}

Hilar cell loss is a characteristic pathological feature observed both in epileptic tissue from humans (Houser, 1999) and in tissue from experimental animals after traumatic brain injury (Lowenstein et al., 1992; Toth et al., 1997), repeated seizures (Cavazos et al., 1994; Buckmaster and Jongen-Relo, 1999), and ischemia (Kotti et al., 1996; Arabadzisz and Freund, 1999). The loss of neurons from the hilus is frequently associated with dentate hyperexcitability (Lowenstein et al., 1992; Toth et al., 1997; Santhakumar et al., 2001), but the precise nature of the relationship between the loss of hilar cells and the development of hyperexcitability in the dentate gyrus is not well understood (Ratzliff et al., 2002). A central question is whether it is the insult-induced functional removal of hilar cells from the neuronal circuit or the reactive changes subsequent to the hilar cell loss (e.g., mossy fiber sprouting, gliosis, and altered gene expression patterns) that lead directly to epileptogenesis. Although insults often lead to reductions in the number of both the glutamatergic mossy cells and the GABAergic hilar interneurons, it is the loss of mossy cells that has

\footnotetext{
Received July 1, 2003; revised Jan. 12, 2004; accepted Jan. 15, 2004

This work was supported by National Institutes of Health Grant NS35915 (I.S.) and by the University of California Irvine Medical Scientist Training Program (A.R., A.H.). We thank R. Zhu for technical assistance.

Correspondence should be addressed to Dr. Ivan Soltesz, Anatomy and Neurobiology, University of California, Irvine, CA 92697. E-mail: isoltesz@uci.edu.

DOI:10.1523/JNEUROSCI.5191-03.2004

Copyright $\odot 2004$ Society for Neuroscience $\quad$ 0270-6474/04/242259-11\$15.00/0
}

been thought to be the key event that results in dentate hyperexcitability, presumably because of the reportedly extreme vulnerability and long associative and commissural connections of mossy cells (for review, see Ratzliff et al., 2002).

One well known theory of epileptogenesis, the "dormant basket cell hypothesis" (Sloviter, 1991, 1994; Sloviter et al., 2003), proposes that the loss of mossy cells results in the excitatory denervation of interneurons, leading to a hypoactive inhibition of granule cells, which in turn underlies dentate hyperexcitability. Although the validity of this mechanism has been disputed on both anatomical and physiological grounds (Wenzel et al., 1997; Bernard et al., 1998), the central idea that the removal of mossy cells from the neuronal network of the dentate gyrus increases granule cell excitability has not been tested experimentally. Initially, the dormant basket cell hypothesis considered the essential neuronal elements of the circuit to be present in a single hippocampal lamella (Sloviter, 1991), but subsequent evolution of the theory expanded the idea to encompass several lamellas (Sloviter, 1994). Specifically, mossy cells postsynaptic to granule cells in one lamella would excite basket cells in neighboring lamellas, leading to inhibition of granule cells in these adjacent lamellas. In this scenario, the loss of mossy cells leads to epilepsy because it results in the collapse of a center-surround inhibitory system organized along the long axis of the hippocampal formation (Sloviter, 1994; for review, see Westbrook, 2000, his Fig. 46-20).

We developed several new techniques, including the cell type- 
specific labeling and ablation of mossy cells in both horizontal and axial slices, to determine whether mossy cell deletion caused hyperexcitability or hypo-excitability in intra- and extra-lamellar granule cell populations. The data show that mossy cells exert an overall excitatory influence on the dentate gyrus and that mossy cell loss alone does not directly underlie epileptogenesis.

\section{Materials and Methods}

Mossy cell labeling. Wistar rats (13-15 d old; Charles River, Wilmington, MA) were placed in a stereotaxic frame under ketamine-xylazine anesthesia. Hamilton syringes were used to inject $1.5 \mu \mathrm{l}$ of $7.5 \%(\mathrm{w} / \mathrm{v})$ fast 3,3'-dilinoleyloxacarbocyanine perchlorate in DMSO (DiO; Molecular Probes, Eugene, OR) at two sites in the right dentate gyrus [site 1: anterior-posterior (AP) from bregma, $-2.4 \mathrm{~mm}$; lateral $(\mathrm{L}), 1.1 \mathrm{~mm}$; ventral $(\mathrm{V}),-3.0 \mathrm{~mm}$; site 2: AP, $-3.4 \mathrm{~mm}$;, $2.6 \mathrm{~mm} ; \mathrm{V},-2.9 \mathrm{~mm}$ ]. DiO-injected rats were killed for physiology 4-7 d after injection. All procedures were performed under protocols approved by the University of California Irvine Institutional Animal Care and Use Committee.

Histology. Rats were perfused with $4 \%$ paraformaldehyde $5 \mathrm{~d}$ after injections, and $50 \mu \mathrm{m}$ horizontal vibratome sections were cut from the left hemisphere (contralateral to injection site). Sections were processed for immunohistochemistry without Triton (Ratzliff and Soltesz, 2001) using the primary antibody rabbit anti-glutamate receptor 2 and/or 3 (GluR2/3) (1:500; $24 \mathrm{hr}, 4^{\circ} \mathrm{C}$; Chemicon, Temecula, CA) and secondary antibody Texas Red-conjugated goat anti-rabbit IgG (1:200; Vector, Burlingame, CA). Controls showed no bleed-through fluorescence. Hilar cells were counted using a fluorescent microscope to determine colocalization of DiO and GluR2/3. For biocytin-filled cells, slices were immersion fixed in $4 \%$ paraformaldehyde and $0.5 \%$ picric acid for $2 \mathrm{~d}$ and resectioned to $50 \mu \mathrm{m}$. The sections were processed as described above using secondary reagents FITC-conjugated goat anti-rabbit IgG (1:400; Vector) and Texas Red-conjugated streptavidin (1:500; Vector). Each biocytin-filled cell was subsequently visualized with $3,3^{\prime}$ diaminobenzidine tetrahydrochloride $(0.015 \%)$ using a standard $\mathrm{ABC}$ kit (Vector) and reconstructed with a camera lucida. All other chemicals were purchased from Sigma (St. Louis, MO).

Preparation of horizontal and axial slices for electrophysiology. Brain slices from the left hemisphere (contralateral to the DiO injections) were prepared as described previously (Toth et al., 1997; Ross and Soltesz, 2000). DiO-injected animals were anesthetized with halothane and decapitated, and the brains were removed and cooled in $4^{\circ} \mathrm{C}$ oxygenated ( $95 \% \mathrm{O}_{2} / 5 \% \mathrm{CO}_{2}$ ) artificial CSF (ACSF) containing (in $\mathrm{mM}$ ): $126 \mathrm{NaCl}$, $2.5 \mathrm{KCl}, 26 \mathrm{NaHCO}_{3}, 2 \mathrm{CaCl}_{2}, 2 \mathrm{MgCl}_{2}, 1.25 \mathrm{NaH}_{2} \mathrm{PO}_{4}$, and 10 glucose. Horizontal brain slices $(350 \mu \mathrm{m})$ were cut on a vibratome under dimmed room light. The horizontal slices originated from the ventral hippocampus $(\mathrm{V},-5.6$ to $-6.6 \mathrm{~mm})$, the same region from which the cell counts in Figure $1 D$ were made (see Fig. $1 A$, inset). For axial sections, the hippocampus was cut along its long axis. The preparation of the axial slices included the hemisection of the brain, removal of the midbrain to reveal the left hippocampus, and the cutting of the cortex parallel to the length of the hippocampus (adapted from Hajos and Mody, 1997). The brain was then glued on the vibratome with the cut side down, and slices were collected as described above. All slices were submerged in oxygenated ACSF at $32^{\circ} \mathrm{C}$ for at least $1 \mathrm{hr}$ in a holding chamber before experimental manipulations. Slices were transferred to a recording chamber perfused with oxygenated ACSF at $35^{\circ} \mathrm{C}$. In some experiments, $20 \mu \mathrm{M}$ bicuculline methiodide and $50 \mu \mathrm{M} \mathrm{SCH}-50911$ (Tocris Cookson, Ellisville, MO) were included in the perfusate.

Systematic procedures for electrophysiological field recordings to minimize variability caused by electrode placement. Field recordings were obtained with patch pipettes containing ACSF. Single-shock stimulation was applied at $0.1 \mathrm{~Hz}$ through a bipolar $90 \mu \mathrm{m}$ tungsten electrode. Because the ablation of the cells (see below) required the transfer of the slice to a different chamber, the recording and stimulating electrodes needed to be removed before and replaced after the ablation. A series of specific steps was developed to ensure reproducibility of the electrode placements before and after the ablation. Essentially, the approach consisted of a combination of detailed micro-mapping of the recording and stimulat- ing electrode positions in each slice and the averaging of multiple responses after repeated placements of the recording electrode in each locus. In horizontal slices, field responses were obtained from the crest of the dentate granule cell layer in a systematic manner, with the stimulating electrode placed in the perforant path outside the molecular layer. A careful map of the location of the stimulating and recording electrodes was drawn for each slice. For the stimulating electrode, the repositioning could be done with certainty because the original placement leaves a small but clearly visible mark in the tissue. For the repositioning of the recording field electrode, carefully noted landmarks (mostly cut blood vessels and any local imperfections in the slice) were used. In addition, for both pre-ablation and post-ablation recordings, the field recording electrode was repositioned (according to the map) five times, and at each of these positions the electrode was lowered into the slice to a depth of 80 $\mu \mathrm{m}$ in the middle of the granule cell layer; four responses were collected with each trial. For analysis, all of these systematically obtained responses were used (without any preselection) to obtain averages to minimize any variability from the replacement of the electrodes. Finally, to exclude any potential bias resulting from the repositioning of the electrodes, a series of "blind" control experiments were also conducted during which the experimenter who performed both the field recordings (including the placement of the electrodes before and after the ablations) and the analysis of the obtained raw data did not know whether the slice had been subjected to a real or a sham ablation. The sham ablation experiments constituted an additional control for moving the slices to and from the recording and ablation chambers ("handling controls"). In the case of the handling controls, the slice was not subjected to ablation or penetration by the pipette.

The stimulus duration was $20 \mu \mathrm{sec}$ in all experiments. For experiments in the horizontal slices, the effects of mossy cell deletions were determined at multiple stimulation intensities (between 1 and $6 \mathrm{~mA}$ ). Because mossy cell deletions resulted in decreases in the field EPSPs (fEPSPs) at all stimulation intensities (see Fig. $3 B$ and Results), in the remainder of the horizontal slice experiments (see Fig. $3 C-I$ ) only the middle stimulation intensity ( $3 \mathrm{~mA}$ ) was used ( $3 \mathrm{~mA}$ stimulation evoked submaximal fEPSP responses in $71 \%$ of the slices and maximal responses in the remaining $21 \%$; the effect of mossy cell deletion was not statistically different between these two groups). In axial slices, granule cell field responses were recorded at two (one intra-lamellar and one extra-lamellar) locations along the septotemporal axis (see Results and Fig. $4 F$ ), with the stimulating electrode placed in the outer molecular layer at the temporal end of the slice, and the stimulation was increased to $8 \mathrm{~mA}$ (i.e., to maximal stimulation intensity, because in these axial slice experiments we wanted to be able to evoke activity from both intra-lamellar and extra-lamellar sites).

Cell type-specific ablations. After pre-ablation field responses were recorded, slices were placed in a submerged chamber perfused with oxygenated ACSF kept at room temperature to minimize excitotoxic damage (Hollrigel et al., 1996). Fluorescently (with DiO) prelabeled mossy cells or granule cell layer-hilar border interneurons [identified on the basis of their characteristic appearance under the infrared-differential interference contrast (IR-DIC) visualization (Ross and Soltesz, 2000)] were targeted and aspirated using a patch pipette, enlarged to $5-10 \mu \mathrm{m}$, containing ACSF. For ablations, only the viable intact cells that showed no obvious signs of swelling were targeted (most of these cells were at least 30 $\mu \mathrm{m}$ below the surface of the slice, and, because of poorer visualization at greater depths, the targeted cells were no more than $70 \mu \mathrm{m}$ from the surface). For the control ablations in which the ablation target was not fluorescent (i.e., in the case of aspirations of granule cell layer-hilar border interneurons and of the hilar neuropil), the slices were still obtained from DiO-injected animals and handled similarly to the mossy cell ablations in every way, including the exposure of the slices to the fluorescent light source for equivalent time periods. Aspiration was repeated two to three times until the soma of the targeted cell disintegrated and was no longer visible (see Fig. $2 \mathrm{~A}$ and Results). The ablation of a single cell took 2-3 min. To standardize the experimental manipulation and minimize slice-to-slice variability, the time for ablation was limited to 40 min, except for those control experiments in which an increased number $(28-30)$ of cells were ablated in $80-90$ min (see Results). After the abla- 

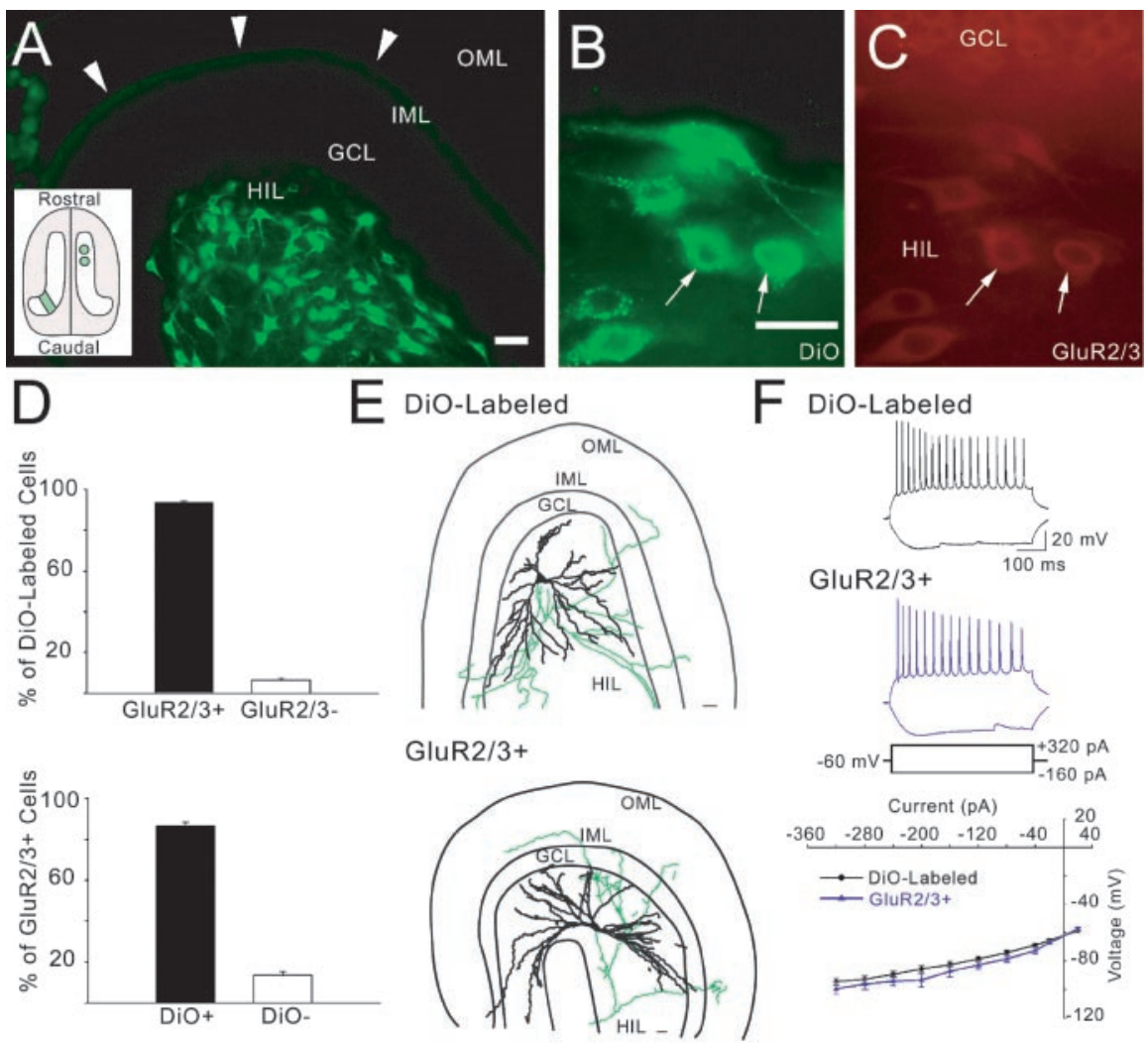

GluR2/3+
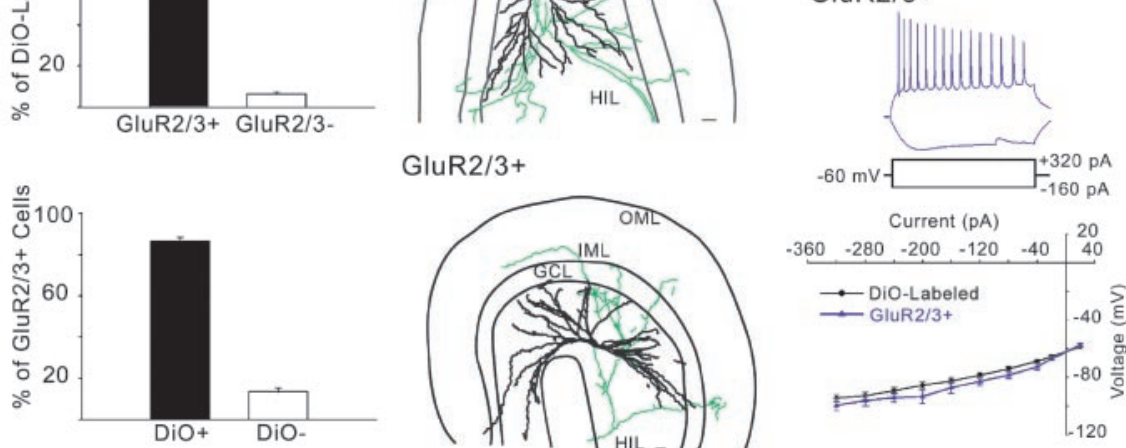

GluR2/3+
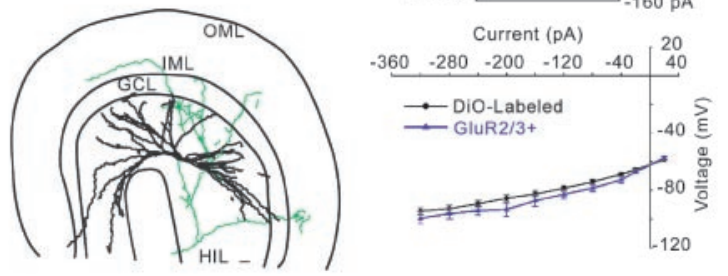

Figure 1. Specific fluorescent labeling of mossy cells. A, Low-magnification image of the left hilus showing cells labeled with Di0 ( green) labeled by a contralateral injection of retrograde tracer. Note that the axonal projections of the mossy cells to the inner molecular layer are clearly visible (arrowheads). Inset, Schematic of the hippocampus in situ shows the injection sites (green circles on the right) and the approximate level used for horizontal slices (green rectangle on the left). Scale bar, $60 \mu \mathrm{m} . B, C$, Histology from injected animals demonstrated that the Di0-labeled cells $(B)$ were immunoreactive for GluR2/3 ( $C$, which strongly stains only the mossy cells in the hilus, as indicated by the arrows. Scale bar, $30 \mu \mathrm{m}$. D, Top, Cell counts revealed that most of the Di0-labeled cells were GluR2/3+; therefore, the retrograde labeling was specific to mossy cells. Bottom, The two contralateral injections labeled the majority of the GluR2/3 + cells on the ipsilateral side, because most of these cells were Di0 labeled. $E$, Camera lucida drawings of biocytin-filled processes from both a Di0-labeled mossy cell (top) and a mossy cell post hoc identified by GluR2/3 immunoreactivity (bottom) showed that both cells exhibit classic anatomical features of mossy cells, including large multipolar somata, dendrites mostly confined to the hilus, and axonal projections to the inner molecular layer (green). Scale bars, $30 \mu \mathrm{m}$. F, Representative whole-cell current-clamp traces from Di0-labeled (top; black) and GluR2/3 + (middle; blue) mossy cells showed similar responses to positive and negative current injections. Bottom, There were no significant differences between the current-voltage curves for the Di0-labeled (black circles) and GluR2/3 + (blue triangles) mossy cells. OML, Outer molecular layer; IML, inner molecular layer; GCL, granule cell layer; HIL, hilus.

tions, the slices were returned to the recording chamber and equilibrated to $35^{\circ} \mathrm{C}$ for $15 \mathrm{~min}$ before post-ablation responses were recorded.

Ethidium homodimer staining. Ethidium homodimer-1 (EthD-1; Molecular Probes) staining was done to identify dead or dying cells as described in Monette et al. (1998). Briefly, $350 \mu \mathrm{m}$ horizontal hippocampal slices from DiO-injected animals were cut as described above for physiology. The slices were allowed to recover in $32^{\circ} \mathrm{C}$ oxygenated ACSF for 1 $\mathrm{hr}$. The slices were subsequently stained with $8 \mu \mathrm{M}$ EthD-1 in oxygenated ACSF for $1 \mathrm{hr}$ at room temperature. The slices were rinsed in oxygenated ACSF at room temperature for $20 \mathrm{~min}$ and then transferred to a submerged chamber perfused with $35^{\circ} \mathrm{C}$ oxygenated ACSF. Each DiOpositive cell was counted and checked for EthD-1 labeling. The $0-30$ and $30-70 \mu \mathrm{m}$ layers were counted separately (see Results for details). For the counts correlating IR-DIC viability with EthD-1 negativity, IR-DICviable, DiO-positive cells were identified and then checked for EthD-1 staining.

Whole-cell recording. Whole-cell recordings were performed using IRDIC visualization techniques as described previously (Ross and Soltesz, 2000). The pipette solution consisted of (in mM): $140 \mathrm{~K}$-gluconate, 2 $\mathrm{MgCl}_{2}$, and $10 \mathrm{HEPES}$, and $0.4 \%$ biocytin (Molecular Probes).

Analysis. Recordings were filtered at $3 \mathrm{kHz}$ before digitization at 20 $100 \mathrm{~ms}$

$\mathrm{kHz}$ by a personal computer for analysis using Strathclyde Electrophysiology Software (courtesy of J. Dempster, University of Strathclyde) and Synapse software (courtesy of Y. De Koninck, Laval University). Data are presented as percentage of pre-ablation values. Statistical analyses, Student's $t$ tests, were performed in SigmaPlot (SPSS Science, Chicago, IL) with a level of significance of $P \leq 0.05$ (indicated by asterisk). Data are presented as mean $\pm \mathrm{SE}$ ( $n$ refers to the number of slices, unless indicated otherwise).

\section{Results \\ Prelabeling and visualization of mossy cells in living slices}

Mossy cells comprise approximately half of the hilar neuronal population (Amaral, 1978), whereas the other half consists of various interneuronal subtypes (Freund and Buzsaki, 1996). Because it is not possible to distinguish mossy cells from neighboring hilar interneurons by morphology alone on the basis of the IR-DIC image and there is no genetic or other marker that labels living mossy cells, we developed a technique to visualize mossy cells for cell-specific ablation experiments. We took advantage of the fact that mossy cells have an extensive contralateral projection (Ribak et al., 1985; Frotscher et al., 1991; Blasco-Ibanez and Freund, 1997) and most of the axons from hilar interneurons are confined to the ipsilateral side (Ribak et al., 1986). To achieve selective mossy cell labeling on the ipsilateral side, the fluorescent dye DiO was injected into the contralateral (right) hippocampus (see Materials and Methods) (Fig. 1A, inset). Ipsilaterally, only hilar cells (and occasional cells in the CA3 region; data not shown) were fluorescently labeled by the contralateral DiO injection (Fig. $1 A$ ). Consistent with the commissural-associational pathway originating from mossy cells, the inner molecular layer (the major target of mossy cell axons) exhibited labeling on the ipsilateral sections (Fig. 1A, arrowheads). Because $\mathrm{DiO}$ is both a retrograde and an anterograde tracer, the labeled axons likely originated from both the contralateral and ipsilateral mossy cells.

The identity of the retrogradely DiO-labeled hilar cells was determined in immunocytochemical experiments using an antibody against GluR2/3, which has been shown to strongly label mossy cells and not interneurons within the hilus (Leranth et al., 1996) (see Discussion). Most of the DiO-labeled hilar cells were positive for GluR2/3 (Fig. $1 B, C$, and top graph in $D$ ) (DiOlabeled hilar cells immunopositive for GluR2/3: $93.6 \pm 1.0 \% ; n=$ 2092 cells from six animals), indicating that most of the retrogradely labeled cells were mossy cells. Additional experiments using biocytin injections into single cells showed that both the DiO-labeled cells ( $n=10$ cells) (Fig. $1 E$, top panel) and the GluR2/3-positive neurons ( $n=7$ cells) (Fig. $1 E$, bottom panel) exhibited the classical features of mossy cells, including multipolar somata, dendrites mostly confined to the hilus, and axon pro- 
jections to the inner molecular layer (Amaral, 1978). The axonal length of the five most completely filled mossy cells covered $21.14 \pm 1.3 \%$ of the inner molecular layer in the $350 \mu \mathrm{m}$ slice, indicating that the main elements of a functional mossy cell circuit is present in the horizontal slice preparation, consistent with previous slice physiology studies (Santhakumar et al., 2000). Note that in vivo single-cell labeling studies also showed mossy cell axons in the inner molecular layer in the lamella where the cell body was located, although most of the axons were targeting distal sites (Buckmaster et al., 1992; Soltesz et al., 1993).

Next, we performed the cell counts from the same material in a reverse manner, i.e., we asked how many of the GluR2/ 3-positive hilar cells were also labeled with DiO. These experiments revealed that most GluR2/3-positive cells in the ipsilateral ventral hippocampus were labeled with $\mathrm{DiO}$ (Fig. $1 D$, bottom panel) (GluR2/ 3-positive hilar cells that were $\mathrm{DiO}$ positive: $85.6 \pm 1.8 \% ; n=2250$ cells from six animals), indicating that just two injections into the contralateral dorsal hippocampus labeled the majority of the mossy cells in the ipsilateral ventral hippocampus (Fig. $1 \mathrm{~A}$, inset) (note that the GluR2/3 and DiO cell counts were from the same region of the ventral hippocampus as the slices for the physiology experiments).

Although previous work indicated that DiO did not alter the physiological properties of labeled neurons (Wang and Lambert, 2003), whole-cell recording experiments were conducted to verify this point. In these experiments, the physiological properties of the DiO-labeled mossy cells were compared with those of unlabeled, post hoc identified GluR2/3-positive, biocytin-filled mossy cells. There was no significant difference in the firing pattern (Fig. $1 F$, top and middle panels), the frequency of action potential firing (average firing frequency in response to a +320 pA current injection: DiO-labeled: $25.2 \pm 4.6 \mathrm{~Hz}, n=8$ cells; GluR2/3+: $31.7 \pm 3.4 \mathrm{~Hz}, n=7$ cells), the sag ratio (ratio between the least and most hyperpolarized voltage during a hyperpolarization caused by a -160 pA current injection: DiO-labeled: $0.81 \pm 0.02$; GluR2/3+: $0.84 \pm 0.02$ ), or the current-voltage curves (Fig. $1 \mathrm{~F}$, bottom panel) between the DiO-labeled and the non-DiO-labeled mossy cells. Taken together, these data indicated that the $\mathrm{DiO}$ prelabeling technique allowed the visualization of functional mossy cells in living slices of the dentate gyrus.

\section{Ablation of mossy cells}

Next, we developed a technique to delete mossy cells from the dentate network in a cell type-specific manner. First, a viable hilar cell was located under IR-DIC visualization, and DiO labeling of the targeted hilar cell was determined under fluorescent light (Fig. $2 A_{1,2}$ ). Next, an enlarged patch pipette was lowered to the identified soma under IR-DIC visualization, and the mossy cell was aspirated using negative-positive pressure cycles two to three times until the soma was disrupted and no longer visible (Fig. $2 A_{3}$ ). Finally, the pipette was removed from the slice; cells adjacent to the ablated cells appeared intact (Fig. $2 A_{4}$ ). An average of $13.5 \pm 0.47$ (range, 11-16) mossy cells were ablated from each horizontal hippocampal slice (for additional details, see Materials and Methods).

\section{Proportion of the ablated mossy cells with respect to the total population of live mossy cells}

An important question concerned the percentage of cells that the ablated mossy cells represented in relation to the total live mossy cell population in the hilus of our $350 \mu \mathrm{m}$ slices. Separate cell counts of DiO-labeled and GluR2/3-positive mossy cells showed that there are $384.3 \pm 24.4$ DiO-labeled and $392 \pm 29.3$ GluR2/ 3 -positive mossy cells in a $350 \mu \mathrm{m}$ slice. However, because mossy cells are thought to be among the most vulnerable neurons in the mammalian brain (Sloviter, 1994), it seemed likely that a proportion of the total mossy cell population that appears as DiO labeled or GluR2/3 positive was not alive and thus did not participate in the electrophysiologically recorded responses. Experiments with EthD-1 fluorescence staining performed on live slices (Monette et al., 1998) (see Materials and Methods) offered a simple technique to determine the proportion of dead or dying mossy cells in the hilus of our $350 \mu \mathrm{m}$ slices. EthD-1 has a high affinity for nucleic acids and is excluded from cells with intact membranes (Haugland, 1996). However, as the membranes of dying cells become permeable, EthD-1 can enter into the cytoplasm and nucleus. After binding to DNA or RNA, the fluorescent intensity of the dye is increased 40-fold (Gaugain et al., 1978; Haugland, 1996). EthD-1 fluorescence could be detected in many but not all DiO-labeled mossy cells (Fig. 2B), and the number of dead or dying cells depended strongly on the distance from the surface. Cell counts showed that $91.6 \pm 2.5 \%$ of DiO-labeled mossy cells exhibited EthD-1 fluorescence in the top $30 \mu \mathrm{m}$ of the slice $(n=$ $325 \mathrm{DiO}$-labeled mossy cells from seven slices), which agreed well with the common experience that the neurons in the top layer in a slice do not appear intact and viable on the basis of the IR-DIC image, and most often cannot be patch clamped (note that, as 

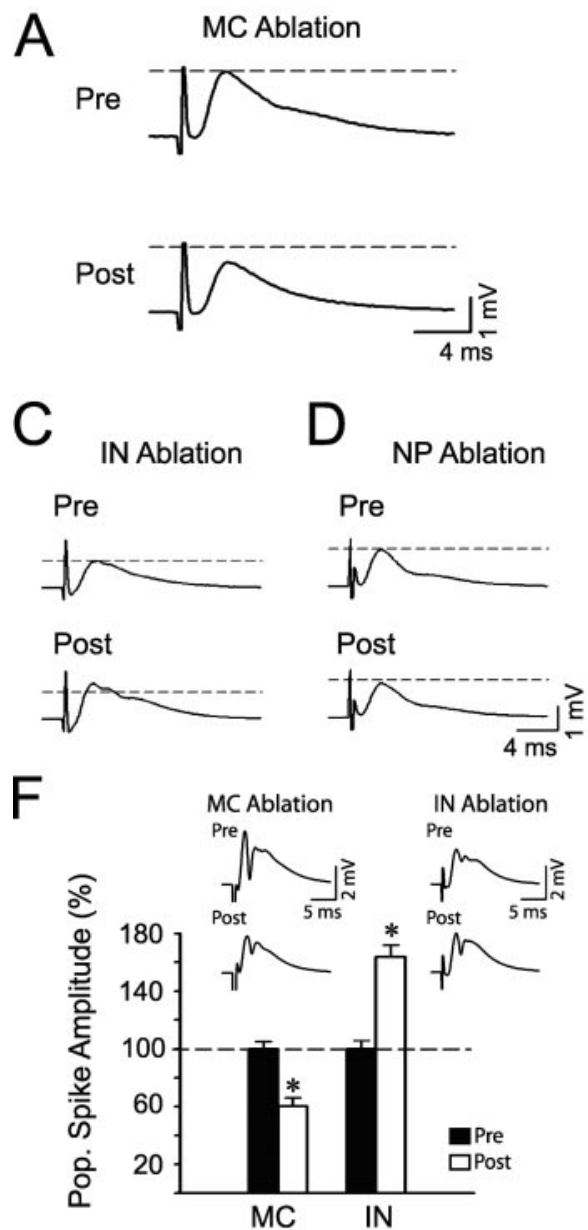

$\mathrm{H}$
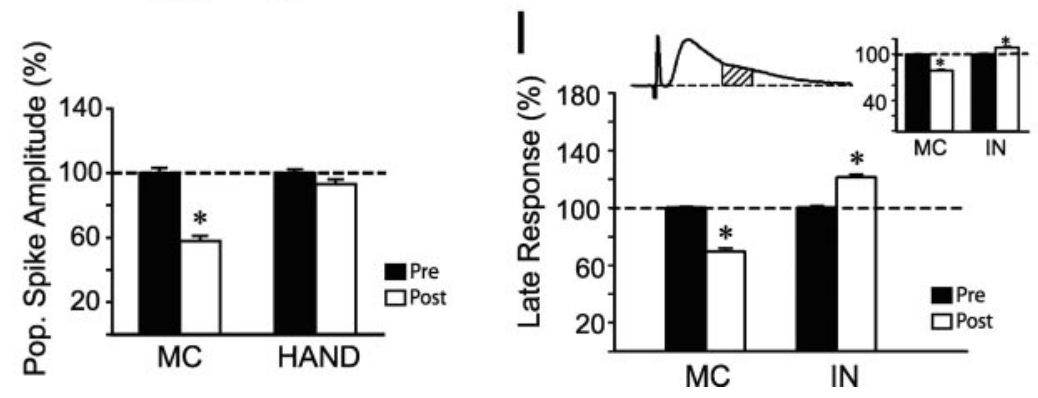

Figure 3. Mossy cell ablation decreases dentate granule cell excitability. A, Representative traces of perforant path evoked fEPSP recordings from the granule cell layer before (Pre; top panel) and after (Post; bottom panel) ablation of mossy cells in a horizontal slice showed decreased fEPSP peak amplitude in response to perforant path stimulation $(3 \mathrm{~mA})$. The dashed line indicates the pre-ablation peak amplitude. $B$, There was a significant decrease in the peak amplitude of the fEPSP after mossy cell ablation at all stimulation intensities. Note that because the minimal stimulation intensity to cause a maximal response was $3 \mathrm{~mA}$, the $3 \mathrm{~mA}$ stimulation strength was used in al subsequent experiments illustrated in this figure. C, Representative traces demonstrating an increase in fEPSP amplitude after the deletion of granule cell layer-hilarborder interneurons. D, Hilar neuropil ablation caused no change in the fEPSP amplitude. Scale bar bottom panel applies to $C$ and $D$. E, Summary plot showing the effects of different ablations on fEPSP amplitude. $F$, The population spike amplitude after mossy cell ablation decreased significantly, whereas it increased after interneuron ablation. The insets show representative traces of the effects of mossy cell (left inset) and interneuron (right inset) ablations on population spike amplitude. G, $H$, Mossy cell ablation experiments performed blind resulted in a decrease in both the fEPSPs $(G)$ and the population spikes $(H)$. The sham ablations performed in these blind experiments constituted a control for transferring slices between the recording and ablation chambers (handling control); note the lack of a change in either fEPSPs $(G$ or population spikes $(H)$ after sham ablations. I, The late component of the field response (between 7 and 10 msec after perforant path stimulation as indicated in the left inset) decreased after mossy cell ablation and increased significantly after interneuron ablation. When traces were normalized to the fEPSP peak amplitude, the late component still decreased after mossy cell ablation and increased after interneuron ablation (right inset). MC, Mossy cell; IN, interneuron; NP, neuropil; HAND, handling control.

mentioned above, the top $30 \mu \mathrm{m}$ was not used for mossy cell ablations). In contrast, in the next $40-\mu \mathrm{m}$-thick layer (i.e., between 30 and $70 \mu \mathrm{m}$ from the surface, where the cell ablations were performed), $36.3 \pm 1.1 \%$ of the DiO-labeled mossy cells were labeled with EthD-1 $(n=576$ cells from seven slices). The population of viable, intact mossy cells as determined by the IR-DIC image (Fig. $2 A$ ) corresponded to those DiO-labeled mossy cells that showed no EthD-1 labeling in these experiments (Fig. 2C).

Because of poor visibility in the living slice below $70 \mu \mathrm{m}$ on either side, no exact cell counts could be performed for $\mathrm{DiO}-$ EthD-1 fluorescence in the middle of the slice. Therefore, the proportion of ablated cells was estimated from the cell counts for the $0-30 \mu \mathrm{m}$ and the $30-70 \mu \mathrm{m}$ layers. We considered three possible scenarios: the middle $210 \mu \mathrm{m}$ was either (1) completely viable, (2) similar to the $30-70 \mu \mathrm{m}$ layer, or (3) completely dead (e.g., because of a progressively poor penetration of nutrients and oxygen into the middle of the slice). If all mossy cells were viable in the middle of the slice, the $n=14$ ablated cells constituted $4.7 \%$ of the total population of the intact mossy cells in the $350 \mu \mathrm{m}$ slice. If the survival rate in the middle of the slice was the same as in the 30-70 $\mu$ m layer, the 14 ablated cells were $6.6 \%$ of the total viable mossy cell population. Finally, if all cells were dead in the middle, $n=14$ ablated mossy cells comprised $22 \%$ of the total number of viable mossy cells in the slice. Therefore, the ablation technique leads to the rapid deletion of at least $4.7 \%$ and at maximum $22 \%$ of the total population of the intact mossy cells in the $350 \mu \mathrm{m}$ slice.

\section{Rapid deletion of mossy cells reduces granule cell excitability}

After these preparatory experiments, the answer to the critical question regarding the physiological consequences of the ablation of mossy cells on granule cell excitability could be determined. After mossy cell deletions, the peak amplitude of the perforant path evoked fEPSP was decreased (fEPSPs, with respect to the preablation baseline: $84.6 \pm 1.1 \% ; n=12$ ) (Fig. $3 A, B, E$ ). Note that the decrease in fEPSPs after mossy cell ablations occurred at all stimulation intensities (Fig. 3B). The synchronous firing of granule cells, as measured by the population spike amplitude, was also significantly decreased after mossy cell ablation [population spike amplitude, with respect to the pre-ablation baseline, at $3 \mathrm{~mA}$ stimulation intensity: $60.2 \pm 5.7 \% ; n=9$ (Fig. $3 F$ ); note that, as shown previously in Toth et al. (1997), because of strong feed-forward inhibition of granule cells, not all slices showed population spike discharges in control ACSF]. These data demonstrated for the first time that mossy cell deletion decreases granule cell excitability. 
Control experiments: interneuronal and neuropil ablations, blind mossy cell ablations, and handling controls

A potential confounding factor in the interpretation of the mossy cell ablation experiments was the possibility that it was ablationrelated, nonspecific tissue damage and not the deletion of mossy cells from the circuit that caused the decrease in the granule cell response. Two controls were designed to test this possibility. First, to control for the effects of the disruption of neuronal somata and the release of intracellular contents into the extracellular space, granule cell layer-hilar border interneurons were ablated, because in the case of interneuronal ablations the outcome could be predicted. As expected with the loss of GABAergic inhibitory cells, the ablation of $15.8 \pm 0.62$ (range, 11-22) interneurons per slice caused significant increases in both the fEPSP $(111.8 \pm 1.2 \% ; n=20)$ (Fig. 3C,E) and the population spike amplitude (163.6 $\pm 8.35 \% ; n=13$ ) (Fig. $3 F)$. Second, we designed a control for the injury to the hilar neuropil. In these experiments, the aspirating pipette was lowered into the slice next to hilar cells ( $14.1 \pm 0.5$ ablations per slice; range, $12-17$; i.e., the number of times the hilar neuropil was ablated was close to the number of ablated mossy cells and interneurons), and the neuropil tissue was aspirated using pressure cycles similar to those used for somatic disruption. These neuropil control ablations caused no significant changes in the fEPSP amplitude (101.9 \pm $1.1 \% ; n=16$ ) (Fig. 3D,E). These two sets of controls indicated that the decrease in the granule cell response after mossy cell ablation was a direct consequence of the loss of mossy cell activity and not a result of nonspecific, indirect damage.

Another set of experiments containing two additional controls was also performed. Mossy cell ablations were performed in a blind manner to avoid potential bias, with the sham ablations serving as handling controls (see Materials and Methods). As shown in Figure 3, $G$ (for fEPSPs) and $H$ (for population spikes), the results of these blind control experiments were similar to the previous mossy cell ablation experiments described above. Namely, the fEPSPs and the population spikes were significantly decreased after the blind mossy cell ablations (fEPSPs: $72.6 \pm$ $2.3 \%, n=4$; population spikes: $57.7 \pm 3.3 \% ; n=4$; the number of mossy cells ablated in these blind experiments: $n=14.8 \pm 0.3$ ), whereas the handling controls showed no significant changes in fEPSP and population spike responses (fEPSPs: $104.6 \pm 3.4 \%$, $n=4$; population spikes: $94.1 \pm 3.0 \%, n=4$ ).

\section{Mossy cell ablations decrease long-latency responses}

The mossy cell ablation results presented above focused on the alterations in the fEPSP and population spike peak amplitudes. Because mossy cells are also likely to participate in polysynaptic responses through their bidirectional connections with granule cells, the longer-latency, presumed polysynaptic components of the fEPSPs were also analyzed. The late component of the fEPSPs (measured as the area under the curve between 7 and $10 \mathrm{msec}$ after perforant path stimulation) (Fig. 3I, left inset) was significantly decreased after mossy cell ablation $(69.6 \pm 2.4 \% ; n=12)$ (Fig. 3I) (these data are from the same experiments as in Fig. 3E). Because the shorter-latency peak fEPSPs showed a decrease after mossy cell ablations (Fig. 3A, B,E) (note that the decrease in the peak fEPSP took place without a change in the rise times of the monosynaptic part of the field response $(<3 \mathrm{msec})$ latency; $10-$ $50 \%$ rise times before ablation: $0.52 \pm 0.03 \mathrm{msec}$; after ablation: $0.55 \pm 0.03 \mathrm{msec} ; n=10$ ), the decrease in the long-latency response was also determined after normalization of the shortlatency peak fEPSP to its pre-ablation level. Even after this normalization, the late component response was decreased after mossy cell ablation (79.6 $\pm 1.1 \% ; n=12)$ (Fig. 3I, right inset). In contrast, the late fEPSP response was significantly increased after the ablation of interneurons [121.3 $\pm 2.1 \%, n=20$ (Fig. 3I); after normalization: $109.4 \pm 1.5 \%, n=20$ (Fig. 3I, right inset)]. These data showed that the net effect of mossy cell activity was excitatory for both the short- and long-latency granule cell responses.

\section{Mossy cells project outside of their parent lamellas in the axial slice preparation}

In the previous experiments performed on horizontal slices, the decreased granule cell activity was measured in the same hippocampal lamella as the ablated mossy cells. Although these results tested the original version of the dormant basket cell hypothesis (Sloviter, 1991), later versions of the hypothesis (Sloviter, 1994) proposed that the major effect of mossy cell loss on granule cell excitability is outside of the lamella that contains the cell body of the mossy cell (Fig. $4 A$ ). Specifically, the dormant basket cell hypothesis predicts a loss of surround inhibition after the deletion of mossy cells in one lamella, leading to the spread of excitation to neighboring lamellas after the activation of the lamella that suffered the mossy cell loss. The width of a hippocampal lamella is thought to be $\sim 600 \mu \mathrm{m}$ (Amaral and Witter, 1989; Andersen et al., 2000), corresponding to the spatial extent of granule cell axons measured from single cell fills in vivo (Buckmaster and Dudek, 1999). The density of axonal processes of mossy cells peaks at $\sim 1 \mathrm{~mm}$ from the mossy cell soma along the septotemporal axis in the rat hippocampus (Buckmaster et al., 1996), with $<5 \%$ of the axons going farther than $2 \mathrm{~mm}$ (Buckmaster and Dudek, 1999, their Fig. 4). Therefore, the axons of mossy cells project outside of the lamella containing the soma into the neighboring lamellas (Fig. 4A) (Soltesz et al., 1993; Buckmaster et al., 1996).

To test the extra-lamellar effects of mossy cell ablation, a nonconventional slice preparation was developed, in which the slice was cut parallel to the septotemporal axis of the dissected hippocampus (Fig. $4 B$ ) (see Materials and Methods; this preparation is referred to as the "axial slice"). An important question was whether the axial slice preparation contained mossy cell axons that innervated the inner molecular layer in lamellas outside of the parent lamella. To answer this question, mossy cells were biocytin filled at the temporal end of the axial slice [228.0 \pm 36 $\mu \mathrm{m}$ from the bottom of the crest of the granule cell layer (Fig. $4 \mathrm{C}$, inset, $4 E$, right column); note that this is the area within which mossy cells were ablated in subsequent experiments; see below]. As shown in Figure $4 C$, mossy cells in the axial slice projected outside of the lamella where the cell body resided, well into the neighboring lamella. The axons of mossy cells in the axial slice innervated the inner molecular layer of the dentate gyrus, where they formed characteristic en passant boutons (presumed sites of synaptic contacts) (Fig. 4C,D). On average, the biocytin-filled and reconstructed mossy cells projected 771.0 $\pm 44 \mu \mathrm{m}(n=6)$ from the soma to the inner molecular layer in the axial slice. Importantly, mossy cells projecting outside of their own lamellas (defined as $300 \mu \mathrm{m}$ on either side of the parent soma) (Fig. $4 \mathrm{~A}$ ) were not rare in this preparation; of the 17 mossy cells that were recovered with at least their cell bodies visualized with biocytin (of a total of 30 attempts), 6 cells had extra-lamellar axons in the inner molecular layer (these 6 cells were included in the morphometric analysis in Fig. 4E). Because the axial slice contained mossy cells that projected into the neighboring lamella, this preparation was used to test the prediction of the dormant basket cell hypothesis that center-surround inhibition collapses in the la- 

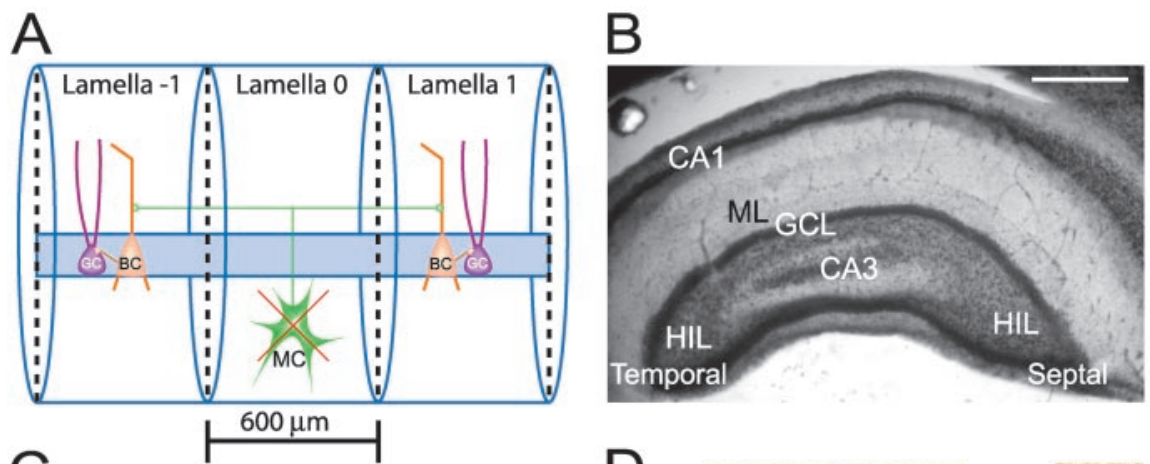
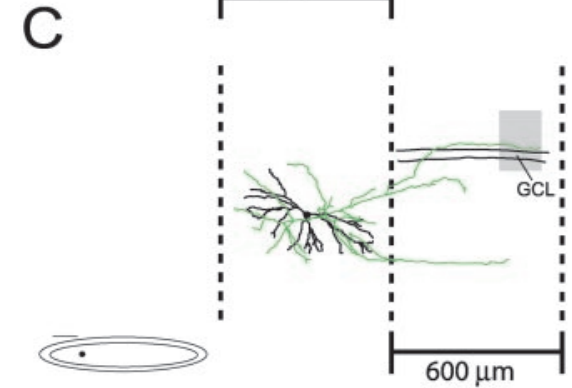

E

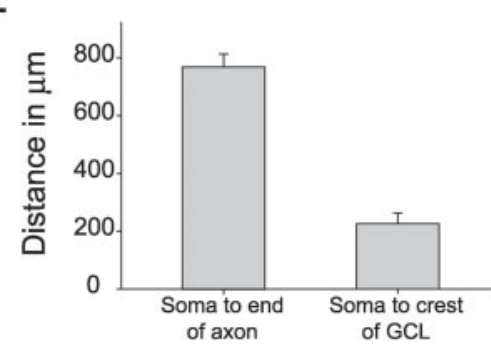

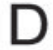

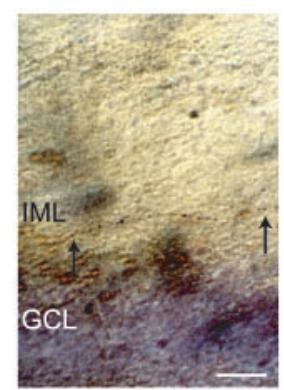

$\mathrm{F}$

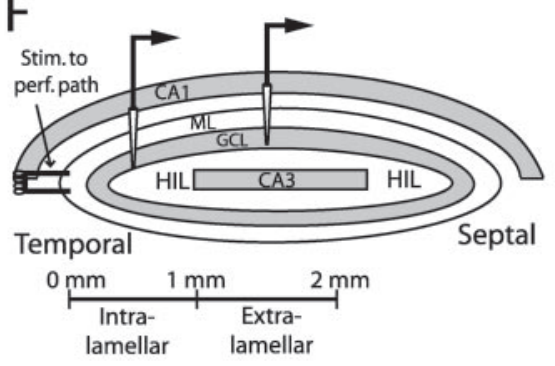

Figure 4. The axial slice preserves the extra-lamellar projections of mossy cells. A, Schematic illustration of the more recent version of the dormant basket cell hypothesis (Sloviter, 1994) that emphasizes the extra-lamellar effects of mossy cell loss. "Lamella 0 " is where the cell body of the mossy cell resides (the width of a hippocampal lamella is $600 \mu \mathrm{m}$, i.e., $300 \mu \mathrm{m}$ on either side of a mossy cell). Note that the dormant basket cell hypothesis predicts the loss of surround inhibition after the deletion of mossy cells in one lamella (indicated by the red X over the mossy cells). MC, Mossy cell; BC, basket cell; GC, granule cell. B, Nissl stain of a typical axial slice used in experiments to determine the effect of mossy cell ablation on remote granule cell responses. Scale bar, $0.5 \mathrm{~mm}$. C, A representative biocytin-filled mossy cell is illustrated from an axial slice, with an axonal projection to the inner molecular layer located in the adjacent lamella (extent of axon from the soma: $823 \mu \mathrm{m}$ ). The inset in the bottom left indicates the position of the cell body in the axial slice. Scale bar: inset, $250 \mu \mathrm{m}$. GCL, Granule cell layer. D, The mossy cell axon in the inner molecular layer from the shaded area in C is shown in situ. The part of the axon that is located between the arrows is shown enlarged in the inset on the right. The en passant axon terminals (sites of presumed synaptic contacts) in the inner molecular layer are indicated by arrowheads. Scale bars, $50 \mu \mathrm{m}$. E, Morphometric analysis of the biocytin-filled mossy cell axons in axial slices. Left column indicates the spatial extent of the axons, and the right column shows that the filled cells were from the area where the mossy cell ablations took place in subsequent experiments (within $300 \mu \mathrm{m}$ from the bottom of the crest of the granule cell layer at the temporal end of the axial slice). F, Schematic of the axial slice indicates the site of perforant path stimulation at the temporal end, and the intra- and extra-lamellar positions of the field potential recordings from the granule cell layer along the longitudinal axis of the hippocampus.

mella adjacent to the lamella with the mossy cell loss (Sloviter, 1994).

The perforant path stimulation and cell type-specific ablations were performed at the temporal end of the axial slice (the ablation was confined to $<300 \mu \mathrm{m}$ from the bottom of the crest of the granule cell layer). Field responses from the granule cell layer were recorded both within and outside of the lamella where the ablations took place (Fig. $4 F$ ). As expected, the average time to peak of the fEPSP increased with distance from the site of stimulation (Fig. $5 \mathrm{~A}$, pre-ablation traces) (time to the peak of the fEPSPs: intra-lamellar: $4.3 \pm 0.1 \mathrm{msec}$; extra-lamellar: $6.8 \pm 0.1$ msec; $n=8$ ). These experiments also served as additional controls for nonspecific damage, because the site of the ablations in the temporal end of the axial slices was spatially separated from the extra-lamellar recording site, i.e., the lamella in which the activity was recorded at the extra-lamellar site was not subjected to ablations and thus did not sustain any direct damage to its hilar neuropil or to the granule cell populations.

\section{Extra-lamellar effects of mossy cell deletion in axial slices}

The ablation of $15.0 \pm 0.91$ (range, 13-17) mossy cells from the temporal end of axial slices caused significant decreases in the fEPSP amplitudes both within and outside of the lamella (intra-lamellar: $72.9 \pm$ 2.3\%; extra-lamellar: $73.5 \pm 3.6 \% ; n=4$ ) (Fig. $5 A, C$ ). Mossy cell ablation also resulted in a significant decrease of the population spike amplitude [intra-lamellar: $80.8 \pm 6.5 \% ; n=3$ (Fig. $5 A, D$ ); note that population spikes were present only in the intra-lamellar position]. In contrast, control ablation of a similar number (15.8 \pm 1.4; range, 14-19) of interneurons in the granule cell layer-hilar border caused a significant increase in the amplitudes of both the fEPSPs (intra-lamellar: $141.4 \pm$ 8.0\%; extra-lamellar: $147.3 \pm 4.0 \% ; n=4)$ (Fig. $5 B, E$ ) and the population spikes (intra-lamellar: $149 \pm 23.1 \% ; n=3$ ) (Fig. $5 B, F)$. These data demonstrated that mossy cell deletion in one lamella resulted in a decrease in granule cell responses even in the neighboring lamella, contrary to the predictions of the dormant basket cell hypothesis.

\section{Ablations of mossy cells and interneurons in GABA receptor antagonists}

Next, mossy cells and interneurons were ablated in axial slices in the presence of the $\mathrm{GABA}_{\mathrm{A}}$ receptor antagonist bicuculline and the $\mathrm{GABA}_{\mathrm{B}}$ receptor antagonist $\mathrm{SCH}$ 50911. If mossy cells cause excitation of granule cells, ablation of mossy cells should still decrease fEPSPs and population spikes, even in the presence of GABA receptor antagonists (note that under these conditions, the slices exhibit hyperexcitable responses caused by the removal of inhibition). In contrast, ablation of interneurons should lead to no change in granule cell responses, unless the ablation causes some nonspecific damage. In addition, we reasoned that the ablation of a higher number of interneurons should be especially likely to reveal signs of nonspecific damage, in the form of a decrease in granule cell responses after interneuronal ablation in GABA receptor antagonists. Therefore, in these experiments (for both mossy cells and interneurons), the number of ablated cells was approximately doubled compared with the previous ablation experiments.

Ablation of $28.7 \pm 0.5$ (range, 27-32) mossy cells in the presence of $\mathrm{GABA}_{\mathrm{A}}$ and $\mathrm{GABA}_{\mathrm{B}}$ receptor antagonists still caused a 
significant decrease in the amplitude of both the fEPSPs (intra-lamellar: $64.4 \pm$ 2.9\%; extra-lamellar: $76.3 \pm 3.2 \% ; n=5$ ) (Fig. $6 A, B$ ) and population spikes (intralamellar: $77.5 \pm 4.9 \%$ ) (Fig. $6 A, C$ ). In contrast, even with the ablation of a large number of interneurons (29.5 \pm 0.5 ; range, 27-31), there was no change in the amplitudes of either the fEPSPs (intra-lamellar: $102.7 \pm 4.3 \%$; extra-lamellar: $100.0 \pm 0.7 \% ; n=8$ ) (Fig. $6 E, F$ ) or the population spikes (intra-lamellar: $105 \pm$ $11.0 \% ; n=8$ ) (Fig. $6 E, G)$ in the presence of GABA receptor antagonists. Additional control experiments determined that ablation of a lower number of cells (close to the $n=14$ used in the rest of the study) in the presence of GABA receptor blockers also led to a decrease in granule cell population responses after mossy cell ablation [73.3 \pm $6.9 \% ; n=4$ slices (Fig. $6 D$ ); number of mossy cells deleted: $n=14.8 \pm 0.3$; note that although the percentage decreases in the responses after the ablation of 14 or 29 mossy cells appear similar, these numbers cannot be compared directly because of the differences in the duration of the ablation experiments]. Similarly, the responses remained unchanged after the ablation of a lower number of interneurons [ $95.5 \pm 6.0 \% ; n=5$ slices (Fig. $6 H$ ); number of interneurons deleted: $n=14.8 \pm 0.3$ ]. These data support the conclusions that the decrease in granule cell responses in the previous mossy cell ablation experiments performed in control ACSF was caused specifically by the deletion of mossy cells from the neuronal circuit and that the effect of mossy cell deletion on granule cell responses was not mediated through changes in the inhibitory input to granule cells.

\section{Discussion}

Rapid and spatially selective nature of the ablation technique The data in this paper provide direct evidence for a net excitatory role of mossy cells in the dentate circuit. The methods used to obtain these data had several advantages. First, prelabeled mossy cells could be identified in living slices without the laborintensive post hoc identification that is normally required to differentiate mossy cells from hilar interneurons (Santhakumar et al., 2000; Ratzliff et al., 2002). Second, the rapid ablation of mossy cells was critical, because the several-day time period needed for the in vivo genetic- or toxin-mediated cell-specific ablation techniques (Shah and Jay, 1993) could have allowed for concurrent confounding changes in protein expression or connectivity, such as mossy fiber sprouting, to occur (Sutula et al., 1988; BrooksKayal et al., 1998). Other approaches, such as laser ablation of single cells, are difficult to apply to cell populations, because it can take up to $10 \mathrm{~min}$ to ablate a single large cell (Liu and Fetcho, 1999). Last, our ablation technique could be targeted in a spatially selective manner to a subset of a neuronal population (e.g., ablation of mossy cells in the temporal end of the slice). This spatial selectivity was crucial in determining the effect of mossy cells on extra-lamellar granule cell populations, and it could not have been achieved with other cell-specific ablation techniques (Lechner et al., 2002).

\section{Relative proportion and identity of deleted mossy cells}

The ethidium homodimer experiments showed that the number of deleted mossy cells constituted minimally $4.7 \%$ and maximally $22 \%$ of the live mossy cell population, numbers that are in general agreement with the significant effects of mossy cell ablations on dentate excitability. Additional factors underlying the significant effects of cell deletions may include the large number of granule cells innervated by single mossy cells (Buckmaster et al., 1996) and by interneurons (Freund and Buzsaki, 1996) and the powerful effects of mossy cell and interneuron discharges on granule cells in double-recording slice experiments (Scharfman, 1995; Kraushaar and Jonas, 2000).

The GluR2/3 immunocytochemical and biocytin-filling experiments indicated that the retrogradely DiO-labeled cells were mossy cells. Although GluR2 subunits can be present on interneurons (Toth and McBain, 1998), the GluR2/3 antibody is still the best available marker for mossy cells in the rat hilus, because the only hilar cells that it stains intensely are mossy cells (Leranth et al., 1996). Furthermore, even when GABAergic cells have commissural projections, the axons are restricted to the equivalent lamella in the contralateral hippocampus (Zappone and Sloviter, 2001) (as shown in Fig. $1 A$, inset, the injection site in our study was located dorsally on the contralateral side, whereas the experiments were performed on labeled mossy cells in the temporal part of the ipsilateral dentate gyrus). Although not all of the DiOlabeled hilar cells were successfully double labeled with GluR2/3, lack of positivity in immunocytochemical experiments does not mean true immunonegativity, i.e., some of the DiO-labeled, GluR2/3-negative cells could have been mossy cells. Finally, even if some of the retrogradely DiO-labeled hilar cells were interneurons, their ablation would have been expected to oppose the hypo-excitability effects seen after the ablation of DiO-labeled cells, given the increases in excitability seen after interneuron ablation. Therefore, the effect of inadvertently deleting some interneurons in the mossy cell ablation experiments would have been to underestimate, not overestimate, the decrease in population responses. 

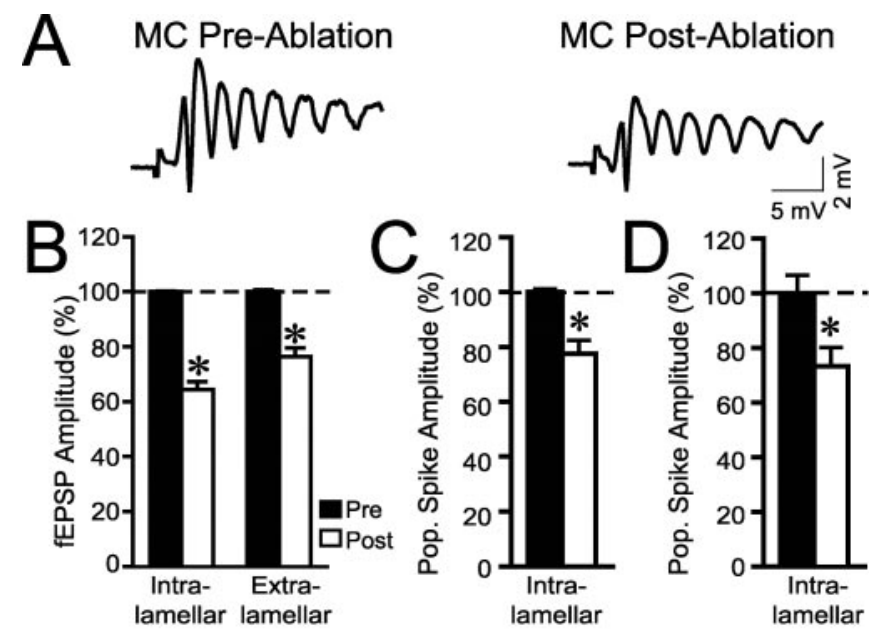
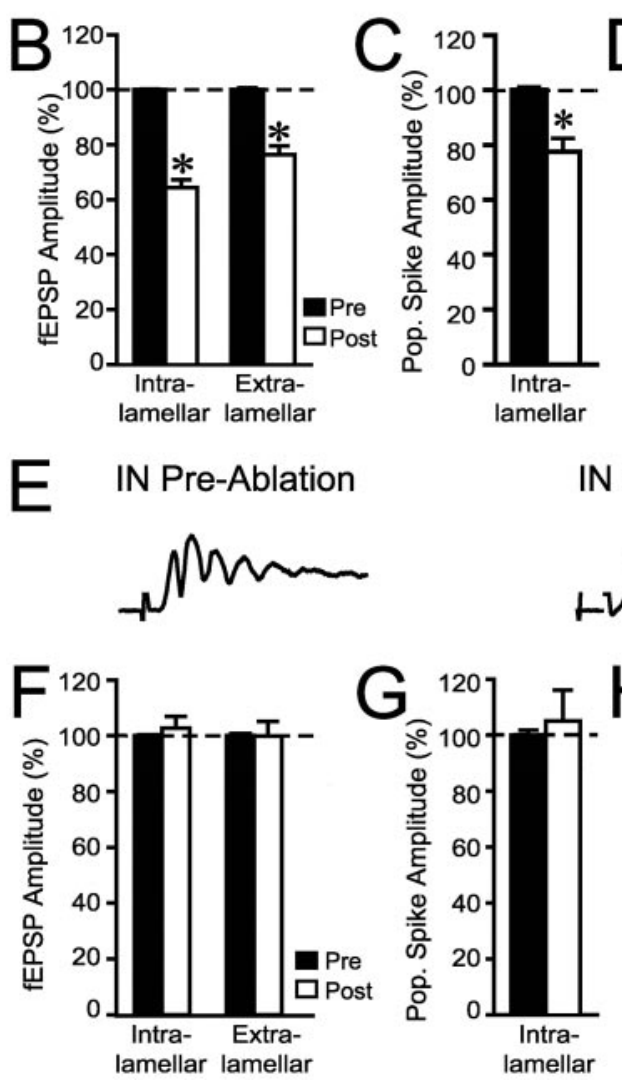

IN Post-Ablation

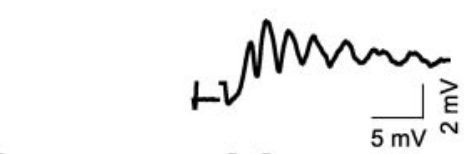

Figure 6. Effects of mossy cell and interneuron deletions on granule cell responses in the presence of GABA receptor antagonists. $A$, The perforant path-evoked field responses were decreased after mossy cell ablation in the presence of $G A B A_{A}$ and $G A B A_{B}$ blockers (experiments done in axial slices; traces are from the intra-lamellar position). Note that the absence of GABAergic input to the granule cells caused a hyperexcitable response to perforant path stimulation. In these experiments (with the exception of $D$ and $H$ ), the number of cells ablated was approximately doubled compared with the experiments shown in Figures 3 and 5. B, Mossy cell ablation ( $\sim 29$ cells; see Results) decreased the amplitude of the fEPSP at both the intra- and extra-lamellar positions. C, $D$, Ablation of either a higher $(n=29 ; C)$ or lower $(n=15 ; D)$ number of mossy cells resulted in a decrease in the first population spike amplitude in GABA receptor antagonists. Note that population spikes were evoked only from the intra-lamellar position. $E$, Representative traces show no change in fEPSPs after interneuron ablation ( $n=29$ ablated cells) in the presence of $G_{A B A_{A}}$ and $G A B A_{B}$ receptor antagonists (traces are from the intra-lamellar position). $F$, Summary data show the lack of an effect of interneuron ablation ( $n=29$ ablated cells) on granule cell fEPSPs at both positions in the presence of GABA receptor antagonists. $G, H$, Ablation of either a higher $(n=29 ; G)$ or lower $(n=15 ; H)$ number of interneurons resulted in no change in the population spike amplitude from the intra-lamellar position in the presence of $\mathrm{GABA}_{\mathrm{A}}$ and $\mathrm{GABA}_{B}$ blockers. MC, Mossy cell; IN, interneuron.

\section{Intra-lamellar and extra-lamellar innervation of the inner} molecular layer by mossy cells in slices

The biocytin-filling experiments demonstrated that the axial slice contains mossy cells with axons that project out of the lamella where their somata reside. The axons of these mossy cells could be found exhibiting multiple en passant terminals in the inner molecular layer in the neighboring lamella. The biocytin-filling experiments also showed that axons from single mossy cells innervate $21 \%$ of the inner molecular layer in horizontal slices, in agreement with in vivo data that demonstrated the presence of mossy cell axons in the inner molecular layer in the same lamella where the cell body was located (Buckmaster et al., 1992; Soltesz et al., 1993).

\section{Controls for the mossy cell ablation experiments}

Control experiments indicated that mossy cell ablations did not result in granule cell hypo-excitability attributable to nonspecific effects. These controls included the ablations of interneurons in both control ACSF and in GABA receptor antagonists, the ablation of mossy cells in a lamella different from the lamella where the granule cell responses were recorded, and the ablations of the hilar neuropil. In addition, blind mossy cell ablation experiments excluded any potential experimenter bias in the repositioning of the recording electrodes or in the analysis. These blind experiments also included sham ablations that were controls for the transfer of slices between the recording and ablation chambers. These distinct control experiments suggest that the ablation method could be used to elucidate the network role for any cell type that can be pre-identified through either retrograde labeling or genetic markers.

\section{Contribution of mossy cells to granule cell excitability}

The excitatory influence of mossy cells on perforant path responses is consistent with electron microscopy data indicating that $>90 \%$ of the total synapses formed by a mossy cell are in the inner molecular layer, and of these synapses $99 \%$ are on dendritic spines belonging to granule cells (Buckmaster et al., 1996; Wenzel et al., 1997). However, because mossy cells do have at least some targets that are GABA positive (Wenzel et al., 1997) and the excitatory inputs to interneurons are frequently powerful (Gulyas et al., 1993; Geiger et al., 1997), the net effect of mossy cells on dentate excitability could not be derived from anatomical data alone.

The results in this study indicate that mossy cells contribute to both the early and late components of granule cell excitability. Although the contribution of mossy cells to the excitation of granule cells at longer latencies after perforant path stimulation is expected from the activation of the well known polysynaptic, recurrent excitatory pathway (perforant path to granule cells to mossy cells and back to granule cells), the mechanism underlying the modulation of the earliest population spike responses by mossy cells possibly differs from this classic pathway. First, mossy cells may influence the short-latency responses through a disynaptic pathway, involving perforant path synapses directly on mossy cell dendrites (15\% of mossy cells in the temporal hippocampus have a dendrite in the molecular layer) (Buckmaster et al., 1992) and the subsequent excitation of granule cells. Action potentials in mossy cells with dendrites in the molecular layer have been shown to occur at very short latencies $(\sim 2 \mathrm{msec})$ after perforant path stimulation, and these short-latency mossy cell discharges occur at lower thresholds than the threshold for granule cell activation (Scharfman, 1991). Second, mossy cells display spontaneous firing at rest both in vitro $[4.5 \pm 1.9 \mathrm{~Hz}$ in Ishizuka and Kosaka (1998); from our experiments, mossy cells recorded in noninvasive cell-attached mode: $2.51 \pm 2.5 \mathrm{~Hz} ; n=4$ cells; data not shown] and in vivo [0.8 $\pm 0.2 \mathrm{~Hz}$ in Soltesz et al. (1993)]. The convergence of many mossy cells onto a single granule cell (Patton and McNaughton, 1995) suggests that spontaneous mossy cell firing could provide tonic excitation to granule cells, the removal of which by the mossy cell ablations may have contributed to the decrease in population spikes. It is interesting to note that the population spikes appeared to be more sensitive to both mossy cell and interneuron ablations compared with fEPSPs 
in all experiments performed in horizontal slices (Fig. 3). This phenomenon is not understood at present, and it is intriguing that it was not observed in axial slices (Figs. 5, 6). Taken together, these data indicate that mossy cells can enhance granule cell excitability through various pathways and mechanisms, leading to alterations in both early and late perforant path evoked responses after mossy cell ablations.

\section{Mossy cell loss and epileptogenesis}

A central question in epilepsy research concerns the neurobiological basis of epileptogenesis in the temporal lobe. Experimental hilar cell loss after trauma or seizures (Lowenstein et al., 1992; Cavazos et al., 1994; Toth et al., 1997; Buckmaster and JongenRelo, 1999; Houser, 1999) frequently occurs concurrently with other modifications, including changes in gene expression (Kapur, 2000; Brooks-Kayal et al., 2001) and alterations in network connectivity caused by axon sprouting (Tauck and Nadler, 1985; Wuarin and Dudek, 2001). However, the relative importance of the loss of cells versus subsequent network changes is not understood. One way to determine the role of the loss of specific cells is to remove these cells in a rapid manner, before changes in gene expression or axon sprouting can take place. Our experiments demonstrate that rapid ablation of mossy cells causes hypoexcitability and not hyperexcitability in granule cell populations located both near and distant to the site of mossy cell lesions. These data do not confirm the predictions of the dormant basket cell hypothesis (Sloviter, 1991, 1994). However, these results are in agreement with alternative mechanistic roles for mossy cells during epileptogenesis (Ratzliff et al., 2002).

\section{References}

Amaral DG (1978) A Golgi study of cell types in the hilar region of the hippocampus in the rat. J Comp Neurol 182:851-914.

Amaral DG, Witter MP (1989) The three-dimensional organization of the hippocampal formation: a review of anatomical data. Neuroscience 31:571-591.

Andersen P, Soleng AF, Raastad M (2000) The hippocampal lamella hypothesis revisited. Brain Res 886:165-171.

Arabadzisz D, Freund TF (1999) Changes in excitatory and inhibitory circuits of the rat hippocampus 12-14 months after complete forebrain ischemia. Neuroscience 92:27-45.

Bernard C, Esclapez M, Hirsch JC, Ben Ari Y (1998) Interneurones are not so dormant in temporal lobe epilepsy: a critical reappraisal of the dormant basket cell hypothesis. Epilepsy Res 32:93-103.

Blasco-Ibanez JM, Freund TF (1997) Distribution, ultrastructure, and connectivity of calretinin-immunoreactive mossy cells of the mouse dentate gyrus. Hippocampus 7:307-320.

Brooks-Kayal AR, Shumate MD, Jin H, Rikhter TY, Coulter DA (1998) Selective changes in single cell GABA(A) receptor subunit expression and function in temporal lobe epilepsy. Nat Med 4:1166-1172.

Brooks-Kayal AR, Shumate MD, Jin H, Rikhter TY, Kelly ME, Coulter DA (2001) gamma-Aminobutyric acid(A) receptor subunit expression predicts functional changes in hippocampal dentate granule cells during postnatal development. J Neurochem 77:1266-1278.

Buckmaster PS, Dudek FE (1999) In vivo intracellular analysis of granule cell axon reorganization in epileptic rats. J Neurophysiol 81:712-721.

Buckmaster PS, Jongen-Relo AL (1999) Highly specific neuron loss preserves lateral inhibitory circuits in the dentate gyrus of kainate-induced epileptic rats. J Neurosci 19:9519-9529.

Buckmaster PS, Strowbridge BW, Kunkel DD, Schmiege DL, Schwartzkroin PA (1992) Mossy cell axonal projections to the dentate gyrus molecular layer in the rat hippocampal slice. Hippocampus 2:349-362.

Buckmaster PS, Wenzel HJ, Kunkel DD, Schwartzkroin PA (1996) Axon arbors and synaptic connections of hippocampal mossy cells in the rat in vivo. J Comp Neurol 366:271-292.

Cavazos JE, Das I, Sutula TP (1994) Neuronal loss induced in limbic pathways by kindling: evidence for induction of hippocampal sclerosis by repeated brief seizures. J Neurosci 14:3106-3121.
Freund TF, Buzsaki G (1996) Interneurons of the hippocampus. Hippocampus 6:347-470.

Frotscher M, Seress L, Schwerdtfeger WK, Buhl E (1991) The mossy cells of the fascia dentata: a comparative study of their fine structure and synaptic connections in rodents and primates. J Comp Neurol 312:145-163.

Gaugain B, Barbet J, Capelle N, Roques BP, Le Pecq JB (1978) DNA Bifunctional intercalators. 2. Fluorescence properties and DNA binding interaction of an ethidium homodimer and an acridine ethidium heterodimer. Biochemistry 17:5078-5088.

Geiger JR, Lubke J, Roth A, Frotscher M, Jonas P (1997) Submillisecond AMPA receptor-mediated signaling at a principal neuron-interneuron synapse. Neuron 18:1009-1023.

Gulyas AI, Miles R, Sik A, Toth K, Tamamaki N, Freund TF (1993) Hippocampal pyramidal cells excite inhibitory neurons through a single release site. Nature 366:683-687.

Hajos N, Mody I (1997) Synaptic communication among hippocampal interneurons: properties of spontaneous IPSCs in morphologically identified cells. J Neurosci 17:8427-8442.

Haugland R (1996) Assays for cell viability, proliferation and function. In: Molecular probes handbook of fluorescent probes and research chemicals (Spence M, ed), pp 366-398. Eugene, OR: Molecular Probes.

Hollrigel GS, Toth K, Soltesz I (1996) Neuroprotection by propofol in acute mechanical injury: role of GABAergic inhibition. J Neurophysiol $76: 2412-2422$.

Houser CR (1999) Neuronal loss and synaptic reorganization in temporal lobe epilepsy. Adv Neurol 79:743-761.

Ishizuka S, Kosaka T (1998) Physiological properties of mouse hippocampal mossy cells. NeuroReport 9:193-199.

Kapur J (2000) Hippocampal neurons express GABA A receptor insensitive to diazepam in hyperexcitable conditions. Epilepsia 41 [Suppl 6]:S86-S89.

Kotti T, Tapiola T, Riekkinen Sr PJ, Miettinen R (1996) The calretinincontaining mossy cells survive excitotoxic insult in the gerbil dentate gyrus. Comparison of excitotoxicity-induced neuropathological changes in the gerbil and rat. Eur J Neurosci 8:2371-2378.

Kraushaar U, Jonas P (2000) Efficacy and stability of quantal GABA release at a hippocampal interneuron-principal neuron synapse. J Neurosci 20:5594-5607.

Lechner HA, Lein ES, Callaway EM (2002) A genetic method for selective and quickly reversible silencing of mammalian neurons. J Neurosci 22:5287-5290.

Leranth C, Szeidemann Z, Hsu M, Buzsaki G (1996) AMPA receptors in the rat and primate hippocampus: a possible absence of GluR2/3 subunits in most interneurons. Neuroscience 70:631-652.

Liu KS, Fetcho JR (1999) Laser ablations reveal functional relationships of segmental hindbrain neurons in zebrafish. Neuron 23:325-335.

Lowenstein DH, Thomas MJ, Smith DH, McIntosh TK (1992) Selective vulnerability of dentate hilar neurons following traumatic brain injury: a potential mechanistic link between head trauma and disorders of the hippocampus. J Neurosci 12:4846-4853.

Monette R, Small DL, Mealing G, Morley P (1998) A fluorescence confocal assay to assess neuronal viability in brain slices. Brain Res Brain Res Protoc 2:99-108.

Patton PE, McNaughton B (1995) Connection matrix of the hippocampal formation: I. The dentate gyrus. Hippocampus 5:245-286.

Ratzliff AD, Soltesz I (2001) Differential immunoreactivity for alphaactinin-2, an $N$-methyl-D-aspartate-receptor/actin binding protein, in hippocampal interneurons. Neuroscience 103:337-349.

Ratzliff AH, Santhakumar V, Howard A, Soltesz I (2002) Mossy cells in epilepsy: rigor mortis or vigor mortis? Trends Neurosci 25:140-144.

Ribak CE, Seress L, Amaral DG (1985) The development, ultrastructure and synaptic connections of the mossy cells of the dentate gyrus. J Neurocytol 14:835-857.

Ribak CE, Seress L, Peterson GM, Seroogy KB, Fallon JH, Schmued LC (1986) A GABAergic inhibitory component within the hippocampal commissural pathway. J Neurosci 6:3492-3498.

Ross ST, Soltesz I (2000) Selective depolarization of interneurons in the early posttraumatic dentate gyrus: involvement of the $\mathrm{Na}(+) / \mathrm{K}(+)$ ATPase. J Neurophysiol 83:2916-2930.

Santhakumar V, Bender R, Frotscher M, Ross ST, Hollrigel GS, Toth Z, Soltesz I (2000) Granule cell hyperexcitability in the early post- 
traumatic rat dentate gyrus: the "irritable mossy cell" hypothesis. J Physiol 524:117-134.

Santhakumar V, Ratzliff AD, Jeng J, Toth K, Soltesz I (2001) Long-term hyperexcitability in the hippocampus after experimental head trauma. Ann Neurol 50:708-717.

Scharfman HE (1991) Dentate hilar cells with dendrites in the molecular layer have lower thresholds for synaptic activation by perforant path than granule cells. J Neurosci 11:1660-1673.

Scharfman HE (1995) Electrophysiological evidence that dentate hilar mossy cells are excitatory and innervate both granule cells and interneurons. J Neurophysiol 74:179-194.

Shah EM, Jay DG (1993) Methods for ablating neurons. Curr Opin Neurobiol 3:738-742.

Sloviter RS (1991) Permanently altered hippocampal structure, excitability, and inhibition after experimental status epilepticus in the rat: the "dormant basket cell" hypothesis and its possible relevance to temporal lobe epilepsy. Hippocampus 1:41-66.

Sloviter RS (1994) The functional organization of the hippocampal dentate gyrus and its relevance to the pathogenesis of temporal lobe epilepsy. Ann Neurol 35:640-654.

Sloviter RS, Zappone CA, Harvey BD, Bumanglag AV, Bender RA, Frotscher M (2003) "Dormant basket cell" hypothesis revisited: relative vulnerabilities of dentate gyrus mossy cells and inhibitory interneurons after hippocampal status epilepticus in the rat. J Comp Neurol 459:44-76.

Soltesz I, Bourassa J, Deschenes M (1993) The behavior of mossy cells of the rat dentate gyrus during theta oscillations in vivo. Neuroscience 57:555-564.
Sutula T, He XX, Cavazos J, Scott G (1988) Synaptic reorganization in the hippocampus induced by abnormal functional activity. Science 239:1147-1150.

Tauck DL, Nadler JV (1985) Evidence of functional mossy fiber sprouting in hippocampal formation of kainic acid-treated rats. J Neurosci 5:1016-1022.

Toth K, McBain CJ (1998) Afferent-specific innervation of two distinct AMPA receptor subtypes on single hippocampal interneurons. Nat Neurosci 1:572-578.

Toth Z, Hollrigel GS, Gorcs T, Soltesz I (1997) Instantaneous perturbation of dentate interneuronal networks by a pressure wave-transient delivered to the neocortex. J Neurosci 17:8106-8117.

Wang X, Lambert NA (2003) Membrane properties of identified lateral and medial perforant pathway projection neurons. Neuroscience 117:485-492.

Wenzel HJ, Buckmaster PS, Anderson NL, Wenzel ME, Schwartzkroin PA (1997) Ultrastructural localization of neurotransmitter immunoreactivity in mossy cell axons and their synaptic targets in the rat dentate gyrus. Hippocampus 7:559-570.

Westbrook GL (2000) Seizures and epilepsy. In: Principles of neural science (Kandel ER, Schwartz JH, Jessell TM, eds), pp 910-935. New York: McGraw-Hill.

Wuarin JP, Dudek FE (2001) Excitatory synaptic input to granule cells increases with time after kainate treatment. J Neurophysiol 85:1067-1077.

Zappone CA, Sloviter RS (2001) Commissurally projecting inhibitory interneurons of the rat hippocampal dentate gyrus: a colocalization study of neuronal markers and the retrograde tracer Fluoro-gold. J Comp Neurol 441:324-344 